\title{
Article \\ Photoelectrochemical Water Oxidation by Cobalt Cytochrome C Integrated-ATO Photoanode
}

\author{
Carla Casadevall ${ }^{1,2, *,+} \mathbb{1}$, Haojie Zhang ${ }^{1}$, Shaojiang Chen ${ }^{1}$, Dayn J. Sommer ${ }^{1}$, Dong-Kyun Seo ${ }^{1, *} \mathbb{C}$ \\ and Giovanna Ghirlanda ${ }^{1, *}$ \\ 1 School of Molecular Sciences, Arizona State University, Tempe, AZ 85287-1604, USA; \\ cubbyzhang@hotmail.com (H.Z.); schen178@asu.edu (S.C.); dsommer@asu.edu (D.J.S.) \\ 2 Institute of Chemical Research of Catalonia (ICIQ), The Barcelona Institute of Science and Technology, \\ Avinguda Països Catalans 16, 43007 Tarragona, Spain \\ * Correspondence: ccasadevall@iciq.es (C.C.); DSeo@asu.edu (D.-K.S.); Giovanna.Ghirlanda@asu.edu (G.G.); \\ Tel.: +44-1223-336396 (C.C.); +33-480-727-7789 (D.-K.S.); +33-480-965-6645 (G.G.) \\ + Present address: Yusuf Hamied Department of Chemistry University of Cambridge, Lensfield Road, \\ CB21EW Cambridge, UK.
}

Citation: Casadevall, C.; Zhang, H.; Chen, S.; Sommer, D.J.; Seo, D.-K.;

Ghirlanda, G. Photoelectrochemical

Water Oxidation by Cobalt

Cytochrome C Integrated-ATO

Photoanode. Catalysts 2021, 11, 626.

https://doi.org/10.3390/catal11050626

Academic Editors: Jose

R. Cabrero-Antonino and Rosa Adam

Received: 1 April 2021

Accepted: 6 May 2021

Published: 12 May 2021

Publisher's Note: MDPI stays neutral with regard to jurisdictional claims in published maps and institutional affiliations.

Copyright: (c) 2021 by the authors. Licensee MDPI, Basel, Switzerland. This article is an open access article distributed under the terms and conditions of the Creative Commons Attribution (CC BY) license (https:/ / creativecommons.org/licenses/by/ $4.0 /)$.

\begin{abstract}
Here, we report the immobilization of Co-protoporphyrin IX (Co-PPIX) substituted cytochrome $c$ (Co-cyt $c$ ) on Antimony-doped Tin Oxide (ATO) as a catalyst for photoelectrochemical oxidation of water. Under visible light irradiation $(\lambda>450 \mathrm{~nm})$, the ATO-Co-cyt $c$ photoanode displays $\sim 6$-fold enhancement in photocurrent density relative to ATO-Co-PPIX at $0.25 \mathrm{~V}$ vs. RHE at $\mathrm{pH}$ 5.0. The light-induced water oxidation activity of the system was demonstrated by detecting evolved stoichiometric oxygen by gas chromatography, and incident photon to current efficiency was measured as $4.1 \%$ at $450 \mathrm{~nm}$. The faradaic efficiency for the generated oxygen was $97 \%$, with a 671 turnover number (TON) for oxygen. The current density had a slow decay over the course of $6 \mathrm{~h}$ of constant irradiation and applied potential, which exhibits the robustness of catalyst-ATO interaction.
\end{abstract}

Keywords: water oxidation; co-cytochrome $c$; semiartificial photosynthesis; antimony-doped tin oxide (ATO); photoelectrochemistry

\section{Introduction}

The efficient conversion of sunlight energy into fuels and chemicals is one of the main goals and challenges to develop a sustainable and renewable future energy system. Photoelectrochemical (PEC) water splitting using semiconductor materials is a promising technology to harvest solar energy in the form of fuel [1-5]. Water splitting comprises two half reactions: (1) water oxidation (WO), in which $\mathrm{O}_{2}, 4 \mathrm{H}^{+}$, and $4 \mathrm{e}^{-}$are generated; and (2) proton reduction, in which $\mathrm{H}_{2}$ is the final product. The bottleneck of the full process is the first step, which occurs on the photoanode and involves multiple electron and proton transfers, as well as $\mathrm{O}-\mathrm{O}$ bond formation, thus requiring a high overpotential [6-8]. Hence, the development of stable and cost-effective photoanodes with high efficiency is a crucial step in designing water splitting systems. One effective approach to overcome the high overpotential barrier of water splitting is the development and study of water oxidation catalysts (WOCs) operating at a low overpotential [7]. In nature, the photoinduced oxidation of water is accomplished at the cubane-like $\mathrm{Mn}_{3} \mathrm{CaO}_{4}$ oxygen evolving center of photosystem II (PS II) $[9,10]$. However, the complexity and sensitivity of PSII hinders its application in devices and has led to extensive efforts for mimicking its function using molecular catalysts [7,10]. Molecular coordination complexes based on ruthenium, iridium, iron, nickel, or cobalt have been reported as efficient WOCs [11-16]. The coordination complexes can be incorporated in heterogeneous materials, resulting in effective long-lasting WOCs under (photo) electrochemical conditions [4,17-19]. In this context, cobalt complexes bearing corrole or porphyrin ligands 
have been shown to catalyze water oxidation, either in the form of homogeneous $[15,20]$ or heterogenized systems [21-26], due to the capacity of porphyrin ligands to stabilize high oxidation states [27]. For instance, Grove et al. reported a Co-porphyrin complex [Co $\left.{ }^{\mathrm{II}}(\mathrm{TDMImp})\left(\mathrm{OH}_{2}\right)\right]$ ([Co-5,10,15,30-tetrakis-(1,3-dimethylimidazolium-2-yl)porphyrin]) active in electrochemical $\mathrm{WO}$ at an onset potential of $1.4 \mathrm{~V}$ (vs. SHE) at pH $7(0.2 \mathrm{M} \mathrm{NaPi}$ buffer), and producing $1400 \mathrm{~s}^{-1}$ [21]. Likewise, Sakai and co-workers reported a Co porphyrin $\mathrm{Co}^{\mathrm{III}} \mathrm{TPPS}$ (TPPS = [meso-tetra(4-sulfonatophenyl)porphyrinato]) in combination with $\left.\mathrm{Ru}^{\mathrm{II}}(\mathrm{bpy})_{3}\right]\left(\mathrm{NO}_{3}\right)_{2}$ (bpy $=2,2^{\prime}$-bipyridine) as photoredox catalyst for photocatalytic WO yielding $122 \mathrm{TON} \mathrm{O}_{2}$ [20]. Porphyrins also act as cofactors in many natural metalloproteins such as cytochromes and can coordinate various transition metals such as $\mathrm{Ni}, \mathrm{Fe}$, $\mathrm{Mn}$, and Co $[28,29]$. Cytochrome $c$ (cyt $c$ ) is a heme binding redox-active protein in which the cofactor is covalently bound through two cysteine residues and axially coordinated by one histidine and one methionine, as shown in Figure 1, and serves as an electron transport component of the respiratory chain of anaerobic specious [30]. The affinity of cyt $c$ to a series of transparent conducting oxides (TCOs), including indium-doped tin oxide (ITO), $\mathrm{WO}_{3}, \mathrm{SnO}_{2}$, and $\mathrm{TiO}_{2}$, has been investigated [31-33], yet its capability to serve as a heterogeneous hybrid catalyst remains unexplored. Among all studied materials, antimony-doped tin oxide (ATO) has emerged as a favored TCO due to its low-cost and excellent optical properties [18]. In addition, ATO's high electrical conductivity combined with its unique large surface area marks it as a promising framework for integrating biomolecules $[18,34,35]$. We previously demonstrated that wild type (WT) cyt $c$ could be absorbed in thin films of highly mesoporous ATO with retention of its native structure and redox properties [36]. Moreover, cobalt porphyrins have been previously interfaced with TCOs and other semiconductors [37-39]. The immobilization strategy for binding cyt $c$ to ATO takes advantage of the electrostatic interaction between substantial negative charges on the metal oxide surface and the protein's positively charged surface, mediated by lysine residues $[40,41]$.

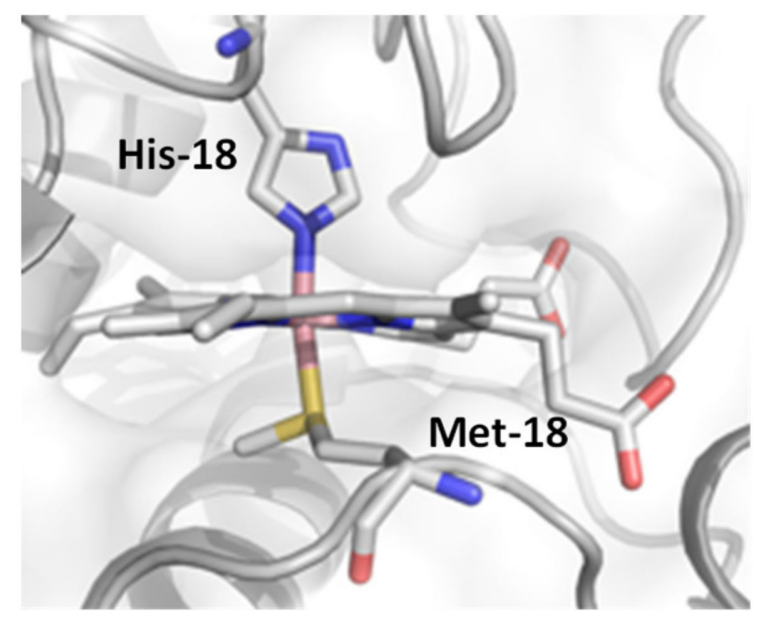

Figure 1. Crystal structure of Co-cyt $c$ active site (PDB 1LFM). Highlighted residues are His/Met biaxial ligands.

In this work, we used a mesoporous ATO- cyt $c$ assembly to develop a catalytic system for photoelectrochemical water oxidation by swapping the iron within the heme active site for cobalt following a transmetalation strategy. We show that the system exhibits a maximum TON of 671 at $\mathrm{pH} 5.0$ with a faradaic efficiency of $97 \%$ in $\mathrm{O}_{2}$ generation. Increased photocurrent density relative to Co-protoporphyrin IX (Co-PPIX) suggests the following: (i) the protein scaffold facilitates absorption to the ATO surface; and (ii) the protein scaffold provides a protecting environment on the active site by slowing down the degradation processes. 


\section{Results and Discussion}

Co-cyt $c$ was obtained by removing iron from WT cyt $c$ via reductive demetallation and the insertion of cobalt by treatment with cobalt acetate [42-44]. The absorption spectrum of the resulting product is consistent with six-coordinated Co (III) porphyrin. Co-cyt $c$ was then deposited on highly mesoporous ATO-coated FTO by soaking the ATO electrode in $50 \mu \mathrm{M}$ solution of the protein in $50 \mathrm{mM}$ tris $\mathrm{pH}$ 7.0, overnight. As shown by UV-vis spectroscopy, the position of the Soret and $Q$ bands remains unchanged upon grafting in the mesoporous ATO (Figure 2), indicating that $\mathrm{Co}-\mathrm{cyt} c$ retains its native structure within the pores.

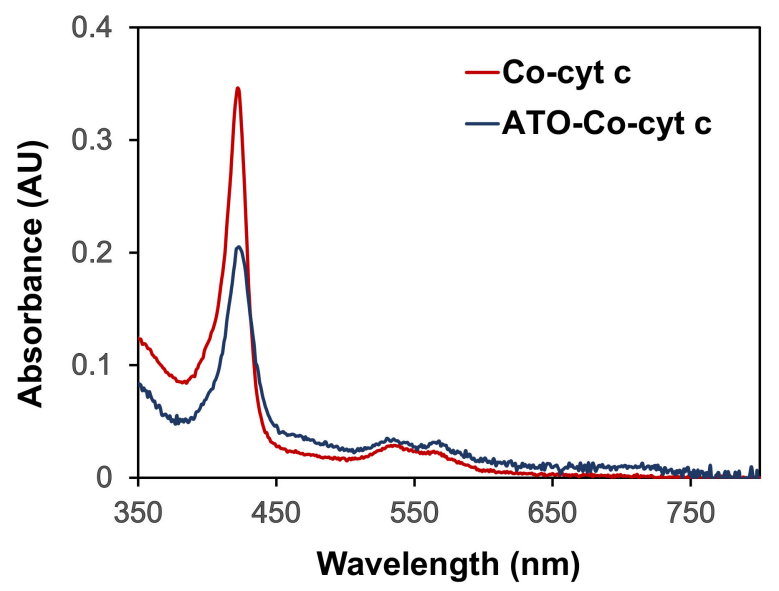

Figure 2. UV-Vis absorption spectra of Co-cyt $c(3.2 \mu \mathrm{M})$ in $100 \mathrm{mM}$ tris, pH 7.5 (red), and Co-cyt $c$ absorbed on ATO coated slide in air (blue). The absorption spectrum of ATO Co-cyt $c$ was multiplied by 3 to improve the visuality. The Soret band maxima at $421 \mathrm{~nm}$ for both Co-cyt $c$ in solution and on ATO represents the six-coordinated Co (III)-porphyrin.

We assessed the integrity of Co-cyt $c$ when absorbed within the pores of ATO by ATR-FTIR spectroscopy. The most intense bands in the IR spectra of proteins, amide I $\left(1600-1700 \mathrm{~cm}^{-1}\right)$ and amide II $\left(1480-1575 \mathrm{~cm}^{-1}\right)$, are sensitive to changes in secondary structure [45]. The comparison of the spectra of Co-cyt $c$ in solution vs. the ATO-absorbed form reveals a similar prominent band $1640 \mathrm{~cm}^{-1}$ from amide I (Figure 3). These results indicate facile binding of Co-cyt $c$ to the ATO, without compromising protein folding [36]. In our conditions ( $\mathrm{pH} 5-7.5$ ), cyt c (isoelectric point of 9.6) is positively charged and thus can be adsorbed on the negatively charged surface of ATO via electrostatic attraction [41].

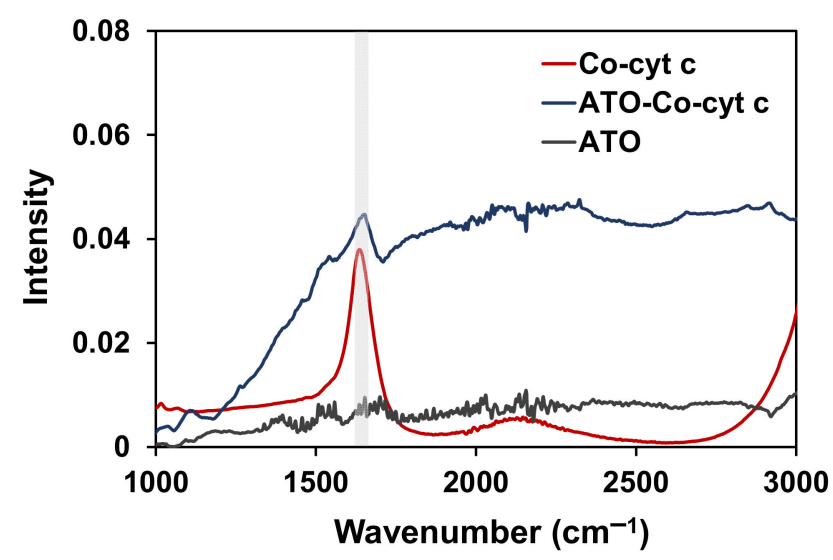

Figure 3. FT-IR spectra of blank ATO (gray), ATO with incorporated Co-cyt $c$ (black), and Co-cyt $c$ in solution (dotted blue). The spectrum of Co-cyt $c$ in solution was taken in $100 \mathrm{mM}$ tris pH 7.5 in liquid IR cell. The spectra for solid samples were obtained directly on the diamond ATR. The IR spectra of ATO-Co-cyt $c$ and Co-cyt $c$ show the characteristic band for amide I at $1640 \mathrm{~cm}^{-1}$. 
The electrochemical activity of ATO-incorporated Co-cyt $c$ was investigated by cyclic voltammetry, revealing a quasi-reversible peak centered at $-0.39 \mathrm{~V} v$ s. RHE, consistent with the $\mathrm{Co}^{\text {(III/II) }}$ redox couple (Figure S1A). Peak separation of $250 \mathrm{mV}$ indicates a relatively slow interfacial electron transfer kinetics. The reduction potential of Co-cyt $c$ in solution was measured to be $-0.48 \mathrm{~V}$ vs. RHE for the Co ${ }^{\text {(III/II) }}$ redox couple (Figure S1C); the similarity between Co-cyt $c^{\prime}$ s redox potential in solution and immobilized on ATO suggests that the protein is in a native conformation.

The linear dependence of the peak current density vs. the scan rate, at scan rates from 40 to $400 \mathrm{mV} \cdot \mathrm{s}^{-1}$ (Figure S2), reflects the expected behavior for surface-immobilized species and indicates the strong binding of Co-cyt $c$ to the ATO surface; in contrast, the absorption of cyt c on ITO surface results in diffusion-limited behavior, as previously reported [26]. Based on the area under the $\mathrm{CV}$ wave of $\mathrm{Co}^{(\mathrm{III} / \mathrm{II})}$ redox couple, we estimated an electrochemically active surface coverage of $2.2 \pm 0.5 \mathrm{nmol} \cdot \mathrm{cm}^{-2}$, which was in a good agreement with previous reports [36]. The total amount of cobalt deposited on the surface was assessed by ICP-MS and corresponded to the average surface coverage of $5.45 \pm 0.48 \mathrm{nmol} \cdot \mathrm{cm}^{-2}$, indicating that approximately $40 \%$ of Co-cyt $c$ in the ATO-Co-cyt $c$ assembly was electroactive. The high loading of Co-cyt $c$ in its electroactive form is in agreement with previously reported studies on cyt c [26]. To build a photoelectrochemical cell (PEC), a three-electrode configuration system was used, consisting of ATO-Co-cyt $c$ as the working photoelectrode, $\mathrm{Pt}$ wire as the counter electrode, and SCE as the reference electrode, under a visible light irradiation source $(\lambda>450 \mathrm{~nm})$. The electrodes were placed in a glass cell, which was sealed with rubber septa and equipped with inlet and outlet syringes for degassing purge system.

First, we optimized the $\mathrm{pH}$, at which the photoelectrocatalytic studies with ATO-Cocyt $c$ should be performed, within the $\mathrm{pH}$ range, where our protein is stable (5-9) [40,46]. The ability of the ATO-Co-cyt $c$ photoanode to generate a photocurrent upon irradiation with a blue light is highest at $\mathrm{pH} 5$ in citrate buffer, resulting in a photocurrent of $55 \mu \mathrm{A} \cdot \mathrm{cm}^{-2}$ when $0.25 \mathrm{~V}$ of potential vs. RHE was applied (Figure 4 ). The positive photocurrent is indicative of electron flow of the electrons from the ATO-Co-cyt $c$ photoanode to the Pt counter electrode, followed by water oxidation by oxidized cobalt in ATO-Co-cyt $c$. Notably, this photocurrent remained stable during $30 \mathrm{~s} \mathrm{light} \mathrm{illumination.}$ The photocurrent observed decreased drastically to $11.6 \mu \mathrm{A} \cdot \mathrm{cm}^{-2}$ upon decreasing the $\mathrm{pH}$ to 5.8 , and values of less than $5 \mu \mathrm{A} \cdot \mathrm{cm}^{-2}$ were recorded at $\mathrm{pH}$ values from 8.9 to 6.4. As shown in Figure 1, Co-PPIX in cyt $\mathrm{c}$ is axially coordinated to a histidine and a methionine. The increase in the generated photocurrent from $11.6 \mu \mathrm{A} \cdot \mathrm{cm}^{-2}$ at $\mathrm{pH} 5.8$ to $48 \mu \mathrm{A} \cdot \mathrm{cm}^{-2}$ at $\mathrm{pH} 5.0$ indicates higher activity of the catalyst, most likely due to the de-coordination of the axial histidine upon protonation, resulting in an open coordination site for the water molecule. Conversely, we can rule out leaching of the Co-PPIX prosthetic group because of its covalent linkage to the protein scaffold. Leaching of the protein is also unlikely in this $\mathrm{pH}$ range because the $\mathrm{pI}$ of cyt $\mathrm{c}$ is 9.6. The data suggest that protonation and de-coordination of the axial histidine are involved in the catalysis, which have been previously postulated with other systems bearing pendant bases $[5,46]$. A similar pendantbase assisted water oxidation mechanism has been observed with a "xanthene-hangman" corrole complex ([Co $\left.{ }^{\mathrm{III}}(\mathrm{bpfxc})\right]$, bpfxc = 5, 15-bis-(pentafluorophenyl)-10-(2,7-di-tert-butyl5-carboxy-9,9-dimethyl-9H-xanthene-4-yl)corrole) that is active for electrocatalytic WO when immobilized in Nafion films, with a TOF close to $0.8 \mathrm{~s}^{-1}$ at $1.6 \mathrm{~V}$ vs. SHE applied potential $(\mathrm{pH}=7)$ [22]. In this study, the authors argued that the hanging moiety assists in the intramolecular proton transfers by preorganizing the water molecule within the system and has a decisive role for water oxidation. Because the water oxidation activity of Co-cyt $c$ is highest at $\mathrm{pH}$ 5.0, we selected citrate buffer at this $\mathrm{pH}$ for further studies. 


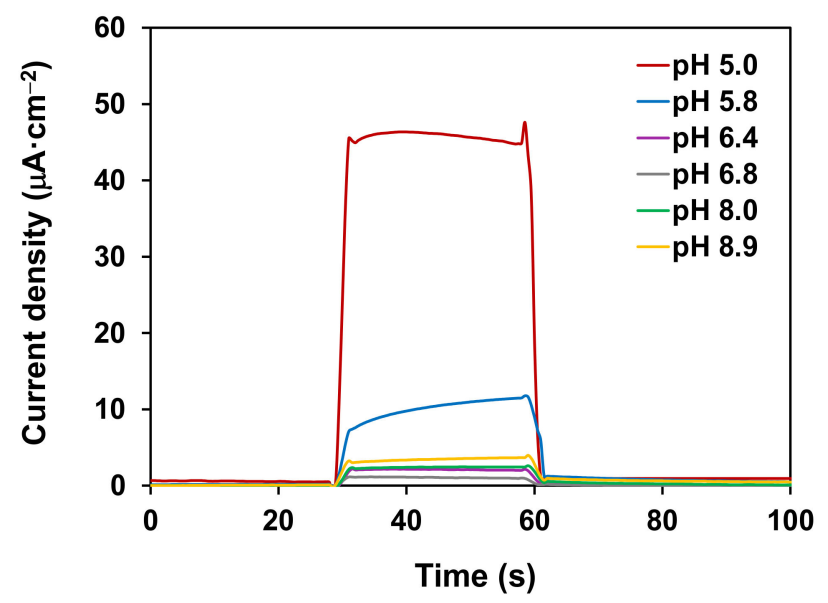

Figure 4. Chronoamperometry experiment with ATO-Co-cyt $c$ at various $\mathrm{pH}$ values. $100 \mathrm{mM}$ citrate buffer was used for $\mathrm{pH}$ 5.0, 5.8, and 6.4, and Tris buffer was used for $\mathrm{pH} 6.8$, 8.0, and 8.9. The applied potential bias was $0.25 \mathrm{~V}$ vs. RHE.

Light/dark photoelectrocatalytic experiments were performed to test the longevity and stability of the system. Upon blue light illumination, the ATO-Co-cyt $c$ photoanode generates an averaged photocurrent of $51 \mu \mathrm{A} \cdot \mathrm{cm}^{-2}$ at $0.25 \mathrm{~V}$ vs. RHE applied potential (Figure 5). The photocurrent remains stable over $30 \mathrm{~s}$ light-on intervals and subsequently decays to zero when the light is off. Moreover, the photocurrent was maintained over $400 \mathrm{~s}$ of light-on/off cycles.

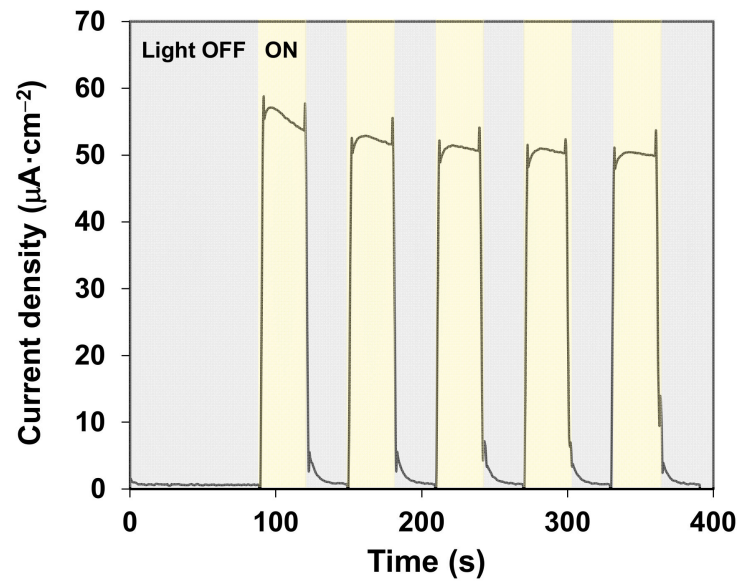

Figure 5. Light on/off photocurrent measurement for ATO-Co-cyt $c$. The data were collected in $100 \mathrm{mM}$ citrate buffer, $1 \mathrm{M} \mathrm{KNO}_{3}, \mathrm{pH}$ 5.0. The applied potential bias was $0.25 \mathrm{~V}$ vs. RHE. The irradiation was performed with a blue light for $30 \mathrm{~s}$ at each cycle.

Increasing the external bias ( $0.5 \mathrm{~V}$ vs. RHE) in the same conditions did not result in higher photocurrent (Figure S4). Bare ATO shows negligible $\left(2 \mu \mathrm{A} \cdot \mathrm{cm}^{-2}\right)$ photocurrent density upon blue light irradiation at $0.25 \mathrm{~V}$ vs. RHE, suggesting ATO-Co-cyt $c$ as the active catalyst.

In order to compare the water oxidation activity of Co-cyt $c$ with Co-PPIX, ATO was incubated in a $50 \mu \mathrm{M}$ solution of Co-PPIX in methanol, overnight. The photocurrent density of ATO-Co-PPIX in citrate buffer was measured and a maximum of $9 \mu \mathrm{A} \cdot \mathrm{cm}^{-2}$ was observed, while ATO-Co-cyt $c$ shows a much stronger signal at the same concentration used for the incubation (Figure 6). To garner more information on the increased activity observed for the protein, we compared the photoelectrocatalytic activity of Co-cyt $c$ and Co-PPIX in solution. We measured a generated photocurrent of $8 \mu \mathrm{A} \cdot \mathrm{cm}^{-2}$ for Co-cyt $c$, while only $2 \mu \mathrm{A} \cdot \mathrm{cm}^{-2}$ was obtained from Co-PPIX at identical $5 \mu \mathrm{M}$ concentration. 


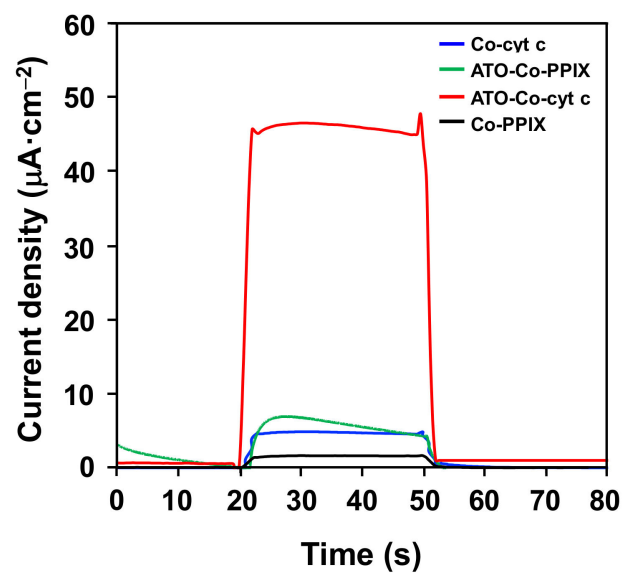

Figure 6. Light control photocurrent measurements in a three-electrode configuration in citrate buffer pH 5.0; applied bias $0.25 \mathrm{~V}$ vs. RHE, with a blue light source. $5 \mu \mathrm{M}$ Co-PPIX in solution (black), $5 \mu \mathrm{M}$ Co-cyt $c$ in solution (blue), ATO-Co-PPIX (green), and ATO-Co-cytc (red).

To investigate whether the difference in photoelectron oxidation reactivity observed in solution could be attributed to the differences in interaction with the electrode, we assessed the diffusion coefficients of Co-PPIX and Co-cyt $c$ in solution using the RandlesSevcik equation,

$$
\mathrm{i}_{\mathrm{p}}=0.446 \mathrm{nFAC} \mathrm{C}^{0}\left(\frac{n F v D_{0}}{R T}\right)^{1 / 2}
$$

where $n$ is the number of transferred electrons, A $\left(\mathrm{cm}^{2}\right)$ the electrode surface area, $\mathrm{C}^{0}$ $\left(\mathrm{mol} \cdot \mathrm{cm}^{-3}\right)$ the analyte bulk concentration, and $D_{0}\left(\mathrm{~cm}^{2} \cdot \mathrm{s}^{-1}\right)$ the diffusion coefficient of the analyte. This equation describes the peak current $i_{p}(A)$ dependence on the square root of scan rate $v\left(\mathrm{~V} \cdot \mathrm{s}^{-1}\right)$ for electrochemically reversible electron transfer processes [47].

The current produced at different scan rates was studied for Co-cyt $c$ and Co-PPIX in solution at the same concentration $(5 \mu \mathrm{M})$ using a three-electrode configuration, where a $0.4 \mathrm{~cm}^{2}$ glassy carbon electrode was used as a working electrode; a SEC as a reference electrode; a Pt wire was used as a counter electrode in $100 \mathrm{mM}$ citrate buffer $\mathrm{pH} 5.0$ and under inert atmosphere; and the current vs. square root of the scan rate was plotted (Figures S5 and S6). The calculated diffusion coefficient from these plots is $1.68 \times 10^{-9}$ and $2.31 \times 10^{-9} \mathrm{~cm}^{2} \cdot \mathrm{s}^{-1}$ for Co-cyt $c$ and Co-PPIX, respectively. The diffusion coefficient is higher for Co-PPIX, ruling out this factor as a driver for the higher photocurrent observed for Co-cyt $c$ in solution and suggesting that the protein environment has a direct effect on enhancing the porphyrin's water oxidation photoelectrocatalytic activity, in line with previous reports for protein-embedded hydrogen production catalysts [48].

Bulk electrolysis for ATO-Co-cyt $c$ photoanode was conducted in a gas-tight photoelectrochemical cell with a three-electrode configuration (Figure S7) in $100 \mathrm{mM}$ citrate buffer at pH $5.0\left(1 \mathrm{M} \mathrm{KNO}_{3}\right.$ supporting electrolyte) with a $0.25 \mathrm{~V}$ vs. RHE applied bias. Stable photocurrent was obtained under blue light irradiation with blue illumination of the photoanode over $1000 \mathrm{~s}$ (Figure 7). The evolution of oxygen and hydrogen was confirmed and measured with gas chromatography (GC-TCD) by taking a sample of the photoelectrochemical cell's headspace at the end of the photo-electrolysis. $1.9 \mu \mathrm{mol} \mathrm{H}_{2}$ and $1.1 \mu \mathrm{mol} \mathrm{O} \mathrm{O}_{2}$ was produced, and a TON of 671 was calculated for $\mathrm{O}_{2}$ generation.

Comparison of the charge passed through the system during the illumination with the amount of generated $\mathrm{O}_{2}$ gives the faradaic efficiency of $97 \%$ for oxygen (Supplementary Materials, for more information). The incident photo-to-current efficiency (IPCE) of the system has also been measured using actinometry (see Supplementary Materials for further details). Using a light source with a wavelength at $450 \mathrm{~nm}$, the calculated IPCE was $4.1 \%$. 


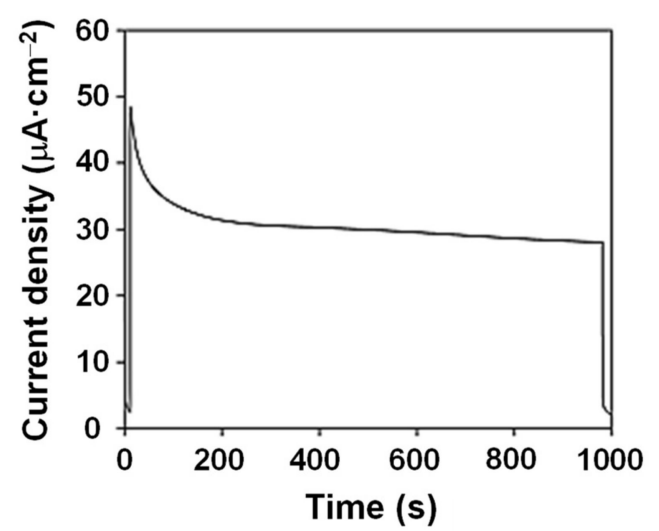

Figure 7. Bulk electrolysis measurement with a $0.25 \mathrm{~V}$ vs. RHE with ATO-Co-cyt $c$ as the working electrode in $100 \mathrm{mM}$ citrate buffer $\mathrm{pH}$ 5.0; illumination was performed with a blue light source.

\section{Materials and Methods}

\subsection{Preparation of ATO Film on FTO Glass}

A previously established sol-gel route for producing highly mesoporous ATO coatings was adapted for the fabrication of macroporous ATO coatings [26,38,40,45,46]. Briefly, a clear solution with $1.00 \mathrm{~g}$ of $\mathrm{SnCl}_{4} \cdot 5 \mathrm{H}_{2} \mathrm{O}$ (Alfa Aesar, 98\%) (Haverhill, MA, USA) and $0.05 \mathrm{~g}$ of $\mathrm{SbCl}_{3}$ (Alfa Aesar, $\geq 99.9 \%$ ) in $6.50 \mathrm{~g}$ of $\mathrm{n}-\mathrm{BuOH}$ and $1.0 \mathrm{~g}$ of deionized water was prepared and cooled to about $4{ }^{\circ} \mathrm{C}$ in ice bath, and then transferred into an Ultra-Turrax tube drive with a rotor stator element. A separate mixture containing $12.4 \mathrm{wt} \%$ carbon black, acetylene (Alfa Aesar, 50\% compressed $\geq 99.9 \%$, surface area $=75 \mathrm{~m}^{2} / \mathrm{g}$, bulk density of $\left.0.095-0.103 \mathrm{~g} / \mathrm{cm}^{3}\right), 25.8 \mathrm{wt} \%$ polyethylene glycol bisphenol A, epichlorohydrin copolymer (PEG) (Sigma-Aldrich (St. Louis, MO, USA), 15-20 kDa), and $61.8 \mathrm{wt} \% \pm$ epichlorohydrin (Fluka (Charlotte, NC, USA), $\geq 99.9 \%$ ) was homogeneously blended in a separate bottle. From this mixture, $6.15 \mathrm{~g}$ was transferred to the metal salt solution in the tube drive. The tube drive was run on speed 3 for $10 \mathrm{~s}$, followed by vigorous shaking. Subsequently, the mixing was carried out with a setting of 6, for $1 \mathrm{~min}$, followed by vigorous shaking, and finally, the tube drive run on the maximum setting, for $1 \mathrm{~min}$, to produce the reaction mixture.

For production of coatings, fluorine-doped tin oxide (FTO, Hartford Glass (Mishawaka, IN, USA), sheet resistance $8 \Omega / \mathrm{sq}$ ) was washed with soapy water and sonicated in an acetone bath. Two opposing edges were masked by applying double-thick transparent tape (Scotch, St. Paul, MN, USA) to cover $1 \mathrm{~mm}$ of the FTO face, and a single layer of tape was applied to a third edge. About $0.25 \mathrm{~mL}$ of the reaction mixture was pipetted on the single tape layer and was drawn smoothly and quickly across the entire slide length with a Pasteur pipet. After drying for $3 \mathrm{~h}$ under ambient conditions, the tubes were placed in a tube furnace that was flushed with oxygen for $1 \mathrm{~h}$, before increasing the temperature to $500{ }^{\circ} \mathrm{C}$. The initially black coatings were calcined at $500{ }^{\circ} \mathrm{C}$ for $5 \mathrm{~h}$ under an oxygen flow to yield translucent, pale blue coatings.

\subsection{Metal Substitution Procedure}

$10 \mathrm{mg}$ lyophilized cyt $\mathrm{c}$ was dissolved in $10 \mathrm{~mL}$ of glacial acetic acid and $500 \mu \mathrm{L}$ of concentrated $\mathrm{HCl}$ was added to the solution (final $\mathrm{pH}=2.2$ ). Working in the dark, the solution was added to a Schlenk flask, and oxygen was removed via 3 freeze-pump-thaw cycles. $100 \mathrm{mg}$ of $\mathrm{FeCl}_{2}$ was added and the solution was refluxed under argon for $8 \mathrm{~h}$ until its color changed from red to purple, indicating a successful demetallation [43]. The acid was removed under vacuum and $2 \mathrm{~mL}$ of water was added and evaporated. The resulting powder was dissolved in $2.5 \mathrm{~mL}$ of $50 \mathrm{mM}$ sodium acetate, $100 \mathrm{mM}$ EDTA, and desalted with Sephadex G-25 PD10 desalting columns [44]. 


\subsection{Cobalt Insertion}

$40 \mathrm{mg}$ cobalt acetate was dissolved in $2 \mathrm{~mL}$ methanol and added to the protein. The solution was degassed with argon and refluxed for $2 \mathrm{~h}$ [42]. Completion of the reaction was detected with the Soret band at $421 \mathrm{~nm}$. The reaction mixture was then purified with RP-HPLC C18 semi-Preparative column (Agilent Technologies, Santa Clara, CA, USA).

\subsection{Incorporation of Co-cyt $C$ into ATO Films}

ATO-coated FTO slides were dried by heating to $180^{\circ} \mathrm{C}$, for $30 \mathrm{~min}$, and cooled to room temperature prior to immersion in the protein solution. The binding of Co-cyt $c$ to the ATO pores was accomplished by incubating the ATO-coated slides in a solution of 50 $\mu \mathrm{M}$ Co-cyt $c$, overnight. The slides were then rinsed with water to remove the physisorbed species and were dried for further experiments.

\subsection{Photocurrent Measurements and Cyclic Voltammetry}

Photoelectrochemical measurements and Cyclic Voltammetry (CV) were performed on a CH-Instruments (Austin, TX, USA) model electrochemical workstation with a threeelectrode configuration containing a SCE reference electrode, a Pt counter electrode, and ATO-Co-cyt working electrode. All scans were performed at $100 \mathrm{mV} / \mathrm{s}$ unless otherwise mentioned. ATO-Co-cyt $c$ slides were illuminated using a Kessil (Richmond, CA, USA) blue lamp.

\subsection{ICP-MS}

To prepare the ICP-MS samples, Co-cyt $c$ functionalized ATO slides were immersed into $10 \mathrm{~mL}$ of concentrated OmniTrace sulfuric acid and heated at $60^{\circ} \mathrm{C}$, for $20 \mathrm{~min}$. The solution was then sonicated for $1 \mathrm{~h}$ and diluted for the measurement. Three samples of Cocyt $c$ functionalized ATO were prepared, as well as a blank ATO as the control. Data were collected from a Thermo-Finnigan Neptune ICP-MS (Thermo Fischer Scientific, Waltham, MA, USA). The reported data are the average of at least 3 replicates.

\subsection{Photoelectrochemical Water Splitting}

All photoelectrochemical water splitting experiments were performed in a threeelectrode configuration, as mentioned before. The electrolyte was $100 \mathrm{mM}$ citrate buffer, $1 \mathrm{M} \mathrm{KNO}_{3} \mathrm{pH} 5.0$, and were purged with argon for $1 \mathrm{~h}$ prior to each test. The evolved hydrogen and oxygen were measured by taking $150 \mu \mathrm{L}$ of the cell's headspace with a gas tight syringe and injected on a GC (SRI instruments (Torrance, CA, USA), Model no. 310C) using a $5 \AA$ molecular sieve column, a TCD detector, and argon carrier gas. The GC calibration was performed using a gas standard $\left(1 \% \mathrm{H}_{2}\right.$ and bulk $\left.\mathrm{N}_{2}\right)$. The reported data are the average of at least 3 replicates.

\subsection{FTIR}

FTIR spectra were recorded on a Bruker instrument (Billerica, MA, USA) by placing the ATO-Co-cyt $c$ on a diamond ATR for surface measurements and putting a drop of Co-cyt $c$ solution in a liquid cell for in-solution measurements.

\section{Conclusions}

In conclusion, we have prepared a new semiartificial photoanode for light-driven water oxidation based on a Co-cyt $c$ supported on highly mesoporous ATO under photoelectrochemical conditions. We found that the incorporation of Co-cyt $c$ onto ATO results in a 5-fold increase in the photoelectrochemical water oxidation to oxygen regarding the free Co-cyt $c$ as well as free or ATO-supported Co-PPIX. These results suggest an increase in the stability of the Co-cyt $c$ catalytic system upon immobilization, as compared with the immobilized Co-PPIX. Nevertheless, further studies may provide a more detailed picture of the mechanism of action. 
Supplementary Materials: The following are available online at https:/ / www.mdpi.com/article/10 $.3390 /$ catal11050626/s1, Figure S1: Cyclic voltammogram of (A) ATO-Co-cyt c, in $100 \mathrm{mM}$ citrate buffer, $1 \mathrm{M} \mathrm{KNO}_{3}, \mathrm{pH} 5.0$ at scan rate of $100 \mathrm{mV} \cdot \mathrm{S}^{-1}$, the redox wave at $-0.34 \mathrm{~V}$ vs SCE $(-0.39$ $\mathrm{V}$ vs RHE) is assigned to Co (III) to Co(II); (B) blank ATO in the same buffer and scan rate; and (C) Co-cyt $c$ in solution in the same buffer and scan rate, the redox wave at $-0.43 \mathrm{~V}$ vs SCE $(-0.48 \mathrm{~V}$ vs RHE) is assigned to $\mathrm{Co}$ (III) to Co(II), Figure S2: Anodic peak current dependence on scan rate for ATO-Co-cyt $c$, in $100 \mathrm{mM}$ citrate buffer, $1 \mathrm{M} \mathrm{KNO}_{3}, \mathrm{pH} 5.0$ at the following scan rates: 40, 100, 150, $200,250,300,350$ and $400 \mathrm{mV} \cdot \mathrm{s}^{-1}$, Figure S3: Linear sweep voltammograms of the working electrode ATO-Co-cyt $c$, in the dark (orange line) and under light illumination (blue line) in $100 \mathrm{mM}$ citrate buffer at pH 5.0, Figure S4: Chronoamperometry behavior of ATO-Co-cyt $c$ at 0.5 (blue) and $0.25 \mathrm{~V}$ (red) vs RHE applied bias in $100 \mathrm{mM}$ citrate buffer at pH 5.0, Figure S5: (A) Cyclic voltammograms of $5 \mu \mathrm{M}$ Co-PPIX in $100 \mathrm{mM}$ citrate buffer, $1 \mathrm{M} \mathrm{KNO}_{3}, \mathrm{pH} 5.0$, at varying scan rates: 50, 80, 100, 200, 250 and $300 \mathrm{mV} \cdot \mathrm{s}^{-1}$, respectively. (B) The Ipc vs square root of scan rate obtained from the data in (A) was used to calculate the diffusion coefficient, Figure S6: (A) Cyclic voltammograms of $5 \mu \mathrm{M} \mathrm{Co-cyt} c$ in $100 \mathrm{mM}$ citrate buffer, $1 \mathrm{M} \mathrm{KNO}_{3}, \mathrm{pH}$ 5.0, at varying scan rates: 50, 80, 100, 150, 200, 250, 300, 350, 400,450 and $500 \mathrm{mV} \cdot \mathrm{s}^{-1}$, respectively. (B) The Ipc vs square root of scan rate obtained from A was used to calculate the diffusion coefficient, Figure S7: Evolution of gas bubbles on the ATO-CocytC working electrode and Pt counter electrode upon illumination.

Author Contributions: C.C., G.G., and D.-K.S. designed the experiments. C.C. and D.J.S. performed the synthesis and experiments. H.Z., S.C., and D.J.S. prepared the ATO Film on FTO Glass. All authors participated in data analysis. C.C. and G.G. wrote the paper with contributions from all authors. All authors have read and agreed to the published version of the manuscript.

Funding: This research received no external funding.

Acknowledgments: This work was supported in part by NSF award 1508301 to G.G. The Spanish Ministerio de Economía y Competitividad (MINECO) is acknowledged for a FPU PhD fellowship (FPU14/02550) to C.C. We would also like to thank Zahra Bahrami-Dizicheh and G. F. Moore for fruitful discussions related to this manuscript.

Conflicts of Interest: The authors declare no conflict of interest.

\section{References}

1. Walter, M.G.; Warren, E.L.; McKone, J.R.; Boettcher, S.W.; Mi, Q.; Santori, E.A.; Lewis, N.S. Solar Water Splitting Cells. Chem. Rev. 2010, 110, 6446-6473. [CrossRef] [PubMed]

2. Reece, S.Y.; Hamel, J.A.; Sung, K.; Jarvi, T.D.; Esswein, A.J.; Pijpers, J.J.H.; Nocera, D.G. Wireless Solar Water Splitting Using Silicon-Based Semiconductors and Earth-Abundant Catalysts. Science 2011, 334, 645. [CrossRef] [PubMed]

3. Sokol, K.P.; Robinson, W.E.; Warnan, J.; Kornienko, N.; Nowaczyk, M.M.; Ruff, A.; Zhang, J.Z.; Reisner, E. Bias-free photoelectrochemical water splitting with photosystem II on a dye-sensitized photoanode wired to hydrogenase. Nat. Energy 2018, 3, 944-951. [CrossRef]

4. Dalle, K.E.; Warnan, J.; Leung, J.J.; Reuillard, B.; Karmel, I.S.; Reisner, E. Electro- and Solar-Driven Fuel Synthesis with First Row Transition Metal Complexes. Chem. Rev. 2019, 119, 2752-2875. [CrossRef]

5. Ye, S.; Ding, C.; Liu, M.; Wang, A.; Huang, Q.; Li, C. Water Oxidation Catalysts for Artificial Photosynthesis. Adv. Mater. 2019, 31, 1902069. [CrossRef]

6. Hisatomi, T.; Kubota, J.; Domen, K. Recent advances in semiconductors for photocatalytic and photoelectrochemical water splitting. Chem. Soc. Rev. 2014, 43, 7520-7535. [CrossRef]

7. Zhang, B.; Sun, L. Artificial photosynthesis: Opportunities and challenges of molecular catalysts. Chem. Soc. Rev. 2019, 48, 2216-2264. [CrossRef]

8. Pannwitz, A.; Klein, D.M.; Rodríguez-Jiménez, S.; Casadevall, C.; Song, H.; Reisner, E.; Hammarström, L.; Bonnet, S. Roadmap towards solar fuel synthesis at the water interface of liposome membranes. Chem. Soc. Rev. 2021, 50, 4833-4855. [CrossRef]

9. Ferreira, K.N.; Iverson, T.M.; Maghlaoui, K.; Barber, J.; Iwata, S. Architecture of the photosynthetic oxygen-evolving center. Science 2004, 303, 1831-1838. [CrossRef]

10. Lubitz, W.; Chrysina, M.; Cox, N. Water oxidation in photosystem II. Photosynth Res. 2019, 142, 105-125. [CrossRef]

11. Abdi, F.F.; van de Krol, R. Nature and Light Dependence of Bulk Recombination in Co-Pi-Catalyzed BiVO4 Photoanodes. J. Phys. Chem. C 2012, 116, 9398-9404. [CrossRef]

12. Zhong, D.K.; Choi, S.; Gamelin, D.R. Near-complete suppression of surface recombination in solar photoelectrolysis by "Co-Pi" catalyst-modified W:BiVO4. J. Am. Chem. Soc. 2011, 133, 18370-18377. [CrossRef]

13. Blakemore, J.D.; Crabtree, R.H.; Brudvig, G.W. Molecular Catalysts for Water Oxidation. Chem. Rev. 2015, 115, 12974-13005. [CrossRef] 
14. Macchioni, A. The Middle-Earth between Homogeneous and Heterogeneous Catalysis in Water Oxidation with Iridium. Eur. J. Inorg. Chem. 2019, 2019, 7-17. [CrossRef]

15. Lloret-Fillol, J.; Costas, M. Chapter One-Water oxidation at base metal molecular catalysts. In Advances in Organometallic Chemistry; Pérez, P.J., Ed.; Academic Press/Elsevier: Cambridge, MA, USA, 2019; Volume 71, pp. 1-52.

16. Casadevall, C.; Bucci, A.; Costas, M.; Lloret-Fillol, J. Chapter Four-Water oxidation catalysis with well-defined molecular iron complexes. In Advances in Inorganic Chemistry; Van Eldik, R., Hubbard, C.D., Eds.; Academic Press/Elsevier: Cambridge, MA, USA, 2019; Volume 74, pp. 151-196.

17. Sayama, K.; Nomura, A.; Arai, T.; Sugita, T.; Abe, R.; Yanagida, M.; Oi, T.; Iwasaki, Y.; Abe, Y.; Sugihara, H. Photoelectrochemical decomposition of water into $\mathrm{H}_{2}$ and $\mathrm{O}_{2}$ on porous $\mathrm{BiVO}_{4}$ thin-film electrodes under visible light and significant effect of $\mathrm{Ag}$ ion treatment. J. Phys. Chem. B 2006, 110, 11352-11360. [CrossRef]

18. Carey, A.-M.; Zhang, H.; Mieritz, D.; Volosin, A.; Gardiner, A.T.; Cogdell, R.J.; Yan, H.; Seo, D.-K.; Lin, S.; Woodbury, N.W. Photocurrent Generation by Photosynthetic Purple Bacterial Reaction Centers Interfaced with a Porous Antimony-Doped Tin Oxide (ATO) Electrode. ACS Appl. Mater. Interfaces 2016, 8, 25104-25110. [CrossRef]

19. Jo, W.; Jang, J.-W.; Kong, K.-J.; Kang, H.J.; Kim, J.; Jun, H.; Parmar, K.; Lee, J.S. Phosphate Doping into Monoclinic BiVO 4 for Enhanced Photoelectrochemical Water Oxidation Activity. Angew. Chem. Int. Ed. Engl. 2012, 124, 3201-3205. [CrossRef]

20. Nakazono, T.; Parent, A.R.; Sakai, K. Cobalt porphyrins as homogeneous catalysts for water oxidation. Chem. Commun. 2013, 49, 6325-6327. [CrossRef]

21. Wang, D.; Groves, J.T. Efficient water oxidation catalyzed by homogeneous cationic cobalt porphyrins with critical roles for the buffer base. Proc. Natl. Acad. Sci. USA 2013, 110, 15579-15584. [CrossRef]

22. Dogutan, D.K.; McGuire, R.; Nocera, D.G. Electocatalytic Water Oxidation by Cobalt(III) Hangman $\beta$-Octafluoro Corroles. J. Am. Chem. Soc. 2011, 133, 9178-9180. [CrossRef]

23. Han, A.; Jia, H.; Ma, H.; Ye, S.; Wu, H.; Lei, H.; Han, Y.; Cao, R.; Du, P. Cobalt porphyrin electrode films for electrocatalytic water oxidation. Phys. Chem. Chem. Phys. 2014, 16, 11224-11232. [CrossRef]

24. Liu, B.; Li, J.; Wu, H.-L.; Liu, W.-Q.; Jiang, X.; Li, Z.-J.; Chen, B.; Tung, C.-H.; Wu, L.-Z. Improved Photoelectrocatalytic Performance for Water Oxidation by Earth-Abundant Cobalt Molecular Porphyrin Complex-Integrated $\mathrm{BiVO}_{4}$ Photoanode. Acs Appl. Mater. Interfaces 2016, 8, 18577-18583. [CrossRef]

25. Sun, Z.; Li, J.; Zheng, H.; Liu, X.; Ye, S.; Du, P. Pyrolyzed cobalt porphyrin-modified carbon nanomaterial as an active catalyst for electrocatalytic water oxidation. Int. J. Hydrog. Energy 2015, 40, 6538-6545. [CrossRef]

26. Daniel, Q.; Ambre, R.B.; Zhang, B.; Philippe, B.; Chen, H.; Li, F.; Fan, K.; Ahmadi, S.; Rensmo, H.; Sun, L. Re-Investigation of Cobalt Porphyrin for Electrochemical Water Oxidation on FTO Surface: Formation of CoOx as Active Species. ACS Catal. 2017, 7, 1143-1149. [CrossRef]

27. Lloret-Fillol, J.; Costas, M. Water oxidation at base metal molecular catalysts. Adv. Organomet. Chem. 2019, 71, 1-52.

28. Hu, X.-M.; Rønne, M.H.; Pedersen, S.U.; Skrydstrup, T.; Daasbjerg, K. Enhanced Catalytic Activity of Cobalt Porphyrin in $\mathrm{CO}_{2}$ Electroreduction upon Immobilization on Carbon Materials. Angew. Chem. Int. Ed. 2017, 56, 6468-6472. [CrossRef]

29. Pasternack, R.F.; Francesconi, L.; Raff, D.; Spiro, E. Aggregation of nickel(II), copper(II), and zinc(II) derivatives of water-soluble porphyrins. Inorg. Chem. 1973, 12, 2606-2611. [CrossRef]

30. Ow, Y.P.; Green, D.R.; Hao, Z.; Mak, T.W. Cytochrome c: Functions beyond respiration. Nat. Rev. Mol. Cell Biol. 2008, 9, 532-542. [CrossRef] [PubMed]

31. Zhang, M.; Zheng, J.; Wang, J.; Xu, J.; Hayat, T.; Alharbi, N.S. Direct electrochemistry of cytochrome c immobilized on one dimensional Au nanoparticles functionalized magnetic $\mathrm{N}$-doped carbon nanotubes and its application for the detection of $\mathrm{H}_{2} \mathrm{O}_{2}$. Sens. Actuators B Chem. 2019, 282, 85-95. [CrossRef]

32. Dong, Y.; Ji, X.; Laaksonen, A.; Cao, W.; He, H.; Lu, X. Excellent Protein Immobilization and Stability on Heterogeneous C-TiO 2 Hybrid Nanostructures: A Single Protein AFM Study. Langmuir 2020, 36, 9323-9332. [CrossRef] [PubMed]

33. Ciornii, D.; Kölsch, A.; Zouni, A.; Lisdat, F. A precursor-approach in constructing 3D ITO electrodes for the improved performance of photosystem I-cyt c photobioelectrodes. Nanoscale 2019, 11, 15862-15870. [CrossRef]

34. Hou, K.; Puzzo, D.; Helander, M.G.; Lo, S.S.; Bonifacio, L.D.; Wang, W.; Lu, Z.-H.; Scholes, G.D.; Ozin, G.A. Dye-Anchored Mesoporous Antimony-Doped Tin Oxide Electrochemiluminescence Cell. Adv. Mater. 2009, 21, 2492-2496. [CrossRef]

35. Carey, A.M.; Zhang, H.; Liu, M.; Sharaf, D.; Akram, N.; Yan, H.; Lin, S.; Woodbury, N.W.; Seo, D.K. Enhancing Photocurrent Generation in Photosynthetic Reaction Center-Based Photoelectrochemical Cells with Biomimetic DNA Antenna. ChemSusChem 2017, 10, 4457-4460. [CrossRef]

36. Kwan, P.; Schmitt, D.; Volosin, A.M.; McIntosh, C.L.; Seo, D.-K.; Jones, A.K. Spectroelectrochemistry of cytochrome c and azurin immobilized in nanoporous antimony-doped tin oxide. Chem. Commun. 2011, 47, 12367-12369. [CrossRef]

37. Day, N.U.; Wamser, C.C. Poly-tetrakis-5,10,15,20-(4-aminophenyl)porphyrin Films as Two-Electron Oxygen Reduction Photoelectrocatalysts for the Production of $\mathrm{H}_{2} \mathrm{O}_{2}$. J. Phys. Chem. C 2017, 121, 11076-11082. [CrossRef]

38. Wadsworth, B.L.; Khusnutdinova, D.; Urbine, J.M.; Reyes, A.S.; Moore, G.F. Expanding the Redox Range of Surface-Immobilized Metallocomplexes Using Molecular Interfaces. ACS Appl. Mater. Interfaces 2020, 12, 3903-3911. [CrossRef]

39. Wadsworth, B.L.; Beiler, A.M.; Khusnutdinova, D.; Reyes Cruz, E.A.; Moore, G.F. Interplay between Light Flux, Quantum Efficiency, and Turnover Frequency in Molecular-Modified Photoelectrosynthetic Assemblies. J. Am. Chem. Soc. 2019, 141, 15932-15941. [CrossRef] 
40. Frasca, S.; von Graberg, T.; Feng, J.-J.; Thomas, A.; Smarsly, B.M.; Weidinger, I.M.; Scheller, F.W.; Hildebrandt, P.; Wollenberger, U. Mesoporous Indium Tin Oxide as a Novel Platform for Bioelectronics. ChemCatChem 2010, 2, 839-845. [CrossRef]

41. Graf, M.; García, R.G.; Wätzig, H. Protein adsorption in fused-silica and polyacrylamide-coated capillaries. Electrophoresis 2005, 26, 2409-2417. [CrossRef]

42. Kleingardner, J.G.; Kandemir, B.; Bren, K.L. Hydrogen Evolution from Neutral Water under Aerobic Conditions Catalyzed by Cobalt Microperoxidase-11. J. Am. Chem. Soc. 2014, 136, 4-7. [CrossRef]

43. Primus, J.L.; Boersma, M.G.; Mandon, D.; Boeren, S.; Veeger, C.; Weiss, R.; Rietjens, I.M. The effect of iron to manganese substitution on microperoxidase 8 catalysed peroxidase and cytochrome P450 type of catalysis. J. Biol. Inorg. Chem. 1999, 4, 274-283. [CrossRef] [PubMed]

44. Dizicheh, Z.B. Design of Redox Proteins as Catalysts for Fuel Production; Arizona State University: Phoenix, AZ, USA, 2019.

45. Mersch, D.; Lee, C.-Y.; Zhang, J.Z.; Brinkert, K.; Fontecilla-Camps, J.C.; Rutherford, A.W.; Reisner, E. Wiring of Photosystem II to Hydrogenase for Photoelectrochemical Water Splitting. J. Am. Chem. Soc. 2015, 137, 8541-8549. [CrossRef] [PubMed]

46. Singh, A.; Mandal, S.; Carey, A.-M.; Liu, M.; Chen, S.; Seo, D.-K.; Yan, H.; Woodbury, N. Interfacing Photosystem I Reaction Centers with a Porous Antimony-Doped Tin Oxide Electrode to Perform Light Driven Redox Chemistry. Biophys. J. 2019, 116, 443a. [CrossRef]

47. Mieritz, D.; Liang, R.; Zhang, H.; Carey, A.-M.; Chen, S.; Volosin, A.; Lin, S.; Woodbury, N.; Seo, D.-K. Thickness-Dependent Bioelectrochemical and Energy Applications of Thickness-Controlled Meso-Macroporous Antimony-Doped Tin Oxide. Coatings 2018, 8, 128. [CrossRef]

48. Call, A.; Casadevall, C.; Romero-Rivera, A.; Martin-Diaconescu, V.; Sommer, D.J.; Osuna, S.; Ghirlanda, G.; Lloret-Fillol, J. Improved Electro- and Photocatalytic Water Reduction by Confined Cobalt Catalysts in Streptavidin. ACS Catal. 2019, 9, 5837-5846. [CrossRef] 